\title{
ASSOCIATION OF ABO AND RH BLOOD GROUPS WITH COVID-19 PCR POSITIVE STATUS: A CASE CONTROL STUDY
}

\author{
Shabana Asif, Aashi Ahmed*, Aliya Batool*, Bushra Anwar*, Ambreen Gul*, Muslim Kayani \\ Islamabad Medical Complex Islamabad Pakistan, *HITEC Institute of Medical Sciences Taxila Pakistan, **Federal Medical \& Dental College, Air University \\ Islamabad Pakistan
}

\begin{abstract}
Objective: To determine association of $\mathrm{ABO}$ and Rh blood groups with COVID-19 RT-PCR positive status. Study Design: Case control study.

Place and Duration of the Study: Department of Pathology, Margalla Hospital Taxila, from Apr 2020 to Dec 2020.

Methodology: The sample comprised of 436 cases and 500 controls. Out of 3936 RT-PCR done during the study duration, 436 RT-PCR positives were enrolled in study as cases. 500 age and gender matched controls were selected from same population. Study variables (age, gender, blood groups, RT-PCR result) were obtained from Hospital data (HIMS). Data was analyzed using SPSS version 25. Mean and SD was calculated for age. Frequencies were calculated for categorical variables. $p$-value calculated applying chi square test. Odds ratios calculated to determine association.

Results: The mean age of cases was $37.3 \pm 16.3$. Statistically significant association was observed between age, gender and COVID-19 RT-PCR positive status. B+ blood group was most frequent both among cases (35.4\%) and controls (36.2\%), followed by $\mathrm{O}+$ and $\mathrm{A}+$. However, no significant association was observed between blood groups and COVID-19 RTPCR positivity. Odds ratios calculated for blood group $\mathrm{O}$ and non - $\mathrm{O}(\mathrm{OR}=0.95)$, A antigen $(\mathrm{OR}=0.97)$ and Rh factor $(\mathrm{OR} 0.93)$ among cases and controls showed week negative association. Whereas a weak positive association of $\mathrm{B}$ antigen + and $\mathrm{B}$ antigen - with PCR positivity (1.07) was observed between cases and controls.

Conclusion: Susceptibility to acquire COVID-19 infection is not associated with ABO and Rh blood groups according to this study.
\end{abstract}

Keywords: ABO blood groups, COVID-19, Rh blood group, RT-PCR, SARS- COV-2.

This is an Open Access article distributed under the terms of the Creative Commons Attribution License (https://creativecommons.org/licenses/by-nc/4.0/), which permits unrestricted use, distribution, and reproduction in any medium, provided the original work is properly cited.

\section{INTRODUCTION}

A zoonotic origin viral infection of SARS-COV-2 emerged in Wuhan, China when a cluster of unexplained pneumonia cases was reported by WHO in Dec 20191. It was labelled as worldwide pandemic on Mar $11,2020^{2}$. The novelty of this virus and lack of literature has led to uncertainty in multiple aspects of this disease $^{3}$. Among them is the association of this viral infection with various biological markers including blood group antigens. International society of blood transfusion has recognized 34 human blood group systems among which $\mathrm{ABO}$ and $\mathrm{Rh}$ blood group antigens are commonly investigated ${ }^{4}$. Difference in blood group antigens expressions can increase or decrease host susceptibility to various bacterial and viral agents 5,6 . Blood group antigens mainly serve as a receptor or co-receptor for infectious agents and many blood group antigens facilitate adhesion, intracellular uptake and signal transduction through organization of microdomains ${ }^{7}$. Previous studies have shown susceptibility of $A B O$ blood groups to bacteria like helicobacter pylori and viruses such as hepatitis B, Norwalk virus and SARS

Correspondence: Dr Ambreen Gul, Associate Professor, National University of Medical Sciences (NUMS) Rawalpindi Pakistan

Received: 25 May 2019; revised received: 09 Feb 2020; accepted: 10 Feb 2020 corona virus ${ }^{8-10}$. In this ongoing pandemic people more susceptible of acquiring this infection should be identified so in future certain characteristics are kept in mind while diagnosing the illness. A recent study from Wuhan, China showed that odds of having SARSCOV-2 infection was more common among A while less among $\mathrm{O}$ blood group of $\mathrm{ABO}$ system ${ }^{11}$. $\mathrm{ABO}$ type was strongly statistically associated with survival following infection ${ }^{12}$. Zietz and Tatonetti found that blood type A was correlated with a higher odds of testing positive for disease while Rh (D) positive blood groups were associated with increased infection and death following infection ${ }^{13}$. ABO allele frequencies have significant correlation with COVID-19 mortality ${ }^{14,15}$. Another study also showed higher risk of acquiring SARSCOV-2 with blood group A and lower risk with O group as compared to non-O groups ${ }^{16}$. COVID-19 infection is found to be associated with blood group A and blood group $\mathrm{O}$ is found to be least prevalent among COVID-19 patients in this part of world ${ }^{17}$.

We undertook this study to understand distribution of blood groups among COVID-19 patients and to determine existence of association of SARS-COV-2 with $\mathrm{ABO}$ blood group in our part of the world. In this study we observed the blood groups in SARS-COV-2 
infected population and compared them with control group fromsame population. The objective is to identify association of increased susceptibility of acquiring COVID-19 infection among certain blood groups. So high risk blood groups are identified as markers of acquiring infection and are dealt accordingly in future for better control and elimination of this public health disease.

\section{METHODOLOGY}

This was a case control study carried out in the department of Pathology, Margalla Hospital Taxila from April-June during first phase of Corona followed by second wave in October to December 2020, after approval of Ethics Review Committee of the hospital. Sample size calculated using WHO sample size calculator for total SARS-COV-2 positive population with a margin of error of $0.05 \%$ and $95 \%$ CI was 430 . All individuals $(\mathrm{n}=3936)$ who were tested for COVID-19 by real-time reverse transcriptase polymerase-chainreaction test (RT-PCR) whether symptomatic, or done for preventive and contact tracing were included in the study after informed consent. Those who tested positive, of all ages and gender $(n=436)$ were taken as cases. Individual who never had COVID-19 infection nor got exposed to COVID-19 positive patient in last 14 days and were free from symptoms of disease were taken as controls. An age and gender matched control group was randomly selected through computer generated random numbers from same population through HMIS data. 500 individuals fulfilling the eligibility criteria were enrolled as controls. Informed consent was taken from control groupand confidentiality was preserved. Study variables (Age, gender, ABO, Rh blood groups, indication of test and test results were obtained from Hospital data record (HMIS) and entered on structured proforma. Nasopharyngeal swabs were collected by trained lab technician after wearing proper PPEs. These samples were then transported to tertiary care center for performance of RT-PCR, in a thermopole container containing ice packs maintaining temperature to 2-8 celsius. Data was analyzed using SPSS version 25. Frequencies were calculated for categorical variables (gender, blood groups). Mean and SD was calculated for age. Odds ratios calculated and chi square test was applied to determine association $(p<0.05)$ between blood groups and COVID-19 positive status.

\section{RESULTS}

Out of 3936, $436(11.1 \%)$ tested positive for PCR were taken as cases, whereas $3500(88.9 \%)$ tested negative. Among cases males were $280(64.2 \%)$ and females were $156(35.7 \%)$. In control group. Four hundred and two $(80.4 \%)$ were male and $98(19.6 \%)$ were females. Statistically significant association was observed between COVID-19 susceptibility and gender $(p=0.001)$ (figure).

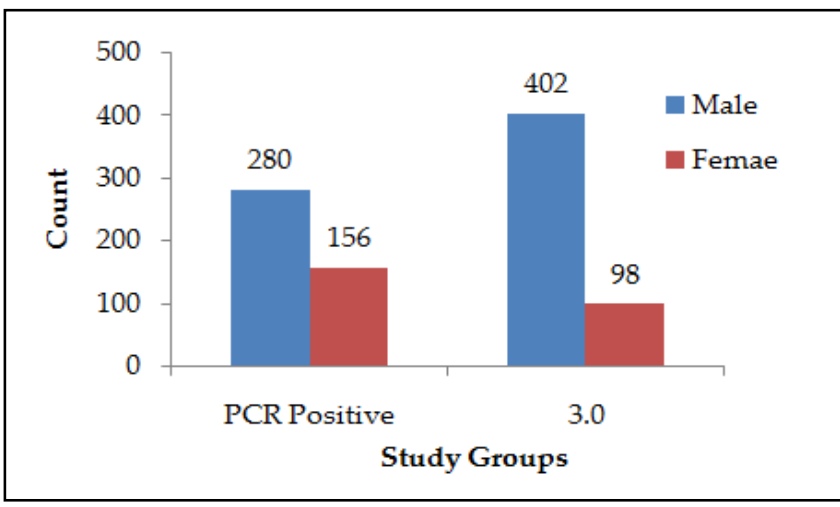

Figure: Distribution of gender among cases and controls.

The mean age of cases was $37.3 \pm 16.3$. Minimum age was 2 months and maximum was 85 years among cases. The mean age of controls was $38.5 \pm 13.7$ years ranging from 1 year to maximum 80 years. A statistically significant association was observed between age categories and study groups (table-I).

Table-I: Age distribution of the study groups.

\begin{tabular}{l|c|c|c|c}
\hline \multirow{2}{*}{$\begin{array}{l}\text { Age } \\
\text { (Years) }\end{array}$} & $\begin{array}{c}|c| \\
\text { Study Participants } \\
\text { Cases } \\
\text { (PCR } \\
\text { Positive) }\end{array}$ & Controls & \multirow{2}{*}{ Total } & $\begin{array}{c}\boldsymbol{p} \text { - } \\
\text { value }\end{array}$ \\
\hline $0-18$ & $68(29.6 \%)$ & $38(0.6 \%)$ & $106(11.3 \%)$ & \\
\hline $19-60$ & $349(79.3 \%)$ & $449(89.8)$ & $798(85.2 \%)$ & \multirow{2}{*}{$0.001^{*}$} \\
\hline$>61$ & $19(8.2 \%)$ & $13(2.6 \%)$ & $32(3.4 \%)$ & \\
\hline Total & 436 & 500 & 936 & \\
\hline
\end{tabular}

*Statistically significant at 0.05

Regarding distribution of blood groups among study groups, majority of patientshaving positive PCR had $\mathrm{B}+(35.4 \%)$, followed by $\mathrm{O}+(27.8 \%)$. However, no significant association was found to exist between blood groups and PCR positivity on comparing control group. Odds that the case had B blood group factor positive versus the odds that the control had B blood group factor positive came out to be 1.07 in this study, which is a very weak positive association (table-II \& III).

\section{DISCUSSION}

Among the various human blood group systems, $\mathrm{ABO}$ blood group system is frequently involved in daily clinical practices. In this study cases and controls had mean (SD) age of 37.3 (16.3) and 38.5 (13.7) years respectively. Minimum and maximum age among 
Table-II: Frequency of $\mathrm{ABO}$ and $\mathrm{Rh}$ blood groups among study groups.

\begin{tabular}{|c|c|c|c|c|}
\hline \multirow{2}{*}{$\begin{array}{l}\text { Blood } \\
\text { Groups }\end{array}$} & \multicolumn{2}{|c|}{ Study Participants } & \multirow{2}{*}{ Total } & \multirow{2}{*}{$\begin{array}{c}p \text { - } \\
\text { value }\end{array}$} \\
\hline & Controls & Cases & & \\
\hline A- & $10(2 \%)$ & $10(2.2 \%)$ & $20(2.1 \%)$ & \multirow{9}{*}{0.82} \\
\hline $\mathrm{A}+$ & $109(21.8 \%)$ & $89(20.4 \%)$ & $198(21.1 \%)$ & \\
\hline AB- & $3(.6 \%)$ & $5(1.1 \%)$ & $8(0.85 \%)$ & \\
\hline $\mathrm{AB}+$ & $36(7.2 \%)$ & $35(8 \%)$ & $71(7.5 \%)$ & \\
\hline B- & $18(3.6 \%)$ & $11(2.5 \%)$ & $29(3.09 \%)$ & \\
\hline $\mathrm{B}+$ & $177(35.4 \%)$ & $158(36.2 \%)$ & $335(35.7 \%)$ & \\
\hline O- & $9(1.8 \%)$ & $11(2.5 \%)$ & $20(2.1 \%)$ & \\
\hline $\mathrm{O}+$ & $139(27.8 \%)$ & $117(26.8 \%)$ & $256(27.3 \%)$ & \\
\hline Total & 500 & 436 & 936 & \\
\hline
\end{tabular}

Table-III: Association of ABO and Rh blood groups with PCR positive status.

\begin{tabular}{|c|c|c|c|}
\hline & Cases & Controls & $\begin{array}{l}\text { Odds } \\
\text { Ratio }\end{array}$ \\
\hline \multicolumn{4}{|c|}{ Association of O blood group with PCR positivity } \\
\hline O Blood group & 117 & 139 & \multirow{2}{*}{0.95} \\
\hline Non - O blood group & 319 & 362 & \\
\hline \multicolumn{4}{|c|}{$\begin{array}{l}\text { Association of } \mathrm{A} \text { antigen }+ \text { and } \mathrm{A} \text { antigen - with PCR } \\
\text { positivity }\end{array}$} \\
\hline A Antigen + & 124 & 145 & \multirow{2}{*}{0.97} \\
\hline A Antigen - & 312 & 356 & \\
\hline \multicolumn{4}{|c|}{$\begin{array}{l}\text { Association of } B \text { antigen }+ \text { and } B \text { antigen - with PCR } \\
\text { positivity }\end{array}$} \\
\hline B Antigen + & 193 & 213 & \multirow{2}{*}{1.07} \\
\hline B Antigen - & 243 & 288 & \\
\hline \multicolumn{4}{|c|}{$\begin{array}{l}\text { Association of Rh negative and Rh-positive factor with } \\
\text { PCR positivity }\end{array}$} \\
\hline Rh Positive & 399 & 460 & \multirow{2}{*}{0.93} \\
\hline Rh Negative & 37 & 40 & \\
\hline
\end{tabular}

cases and controls was 2 months to 85 years and 1-80 years respectively. Similar age distribution was reported in an Iranian study, in which ages ranged from 1595 years and from 4-93 years among patients and controls. Mean (SD) age of patients and controls was 58.81 (15.4) and 48.53 (17.9) years, respectively ${ }^{18}$. No significant difference was observed among mean age of cases and controls in present study. This finding refutes the higher risk of infection with SARS-CoV-2 among older population in our setting as reported in Iranian study $(p<0.001)$. In this study, distribution of cases according to blood groups showed that maximum cases belonged to blood group B (39\%) followed by O (29.6\%), A $(23.8 \%)$ and $\mathrm{AB}(7.8 \%)$. Contrary to this, frequency of blood group A (40.4\%) was highest followed by blood group $\mathrm{O}(35.6 \%)$ and then blood group $\mathrm{B}(17.1 \%)$ and $\mathrm{AB}(6.8 \%)$ in a Lebanese study ${ }^{19}$.

In this study the $\mathrm{ABO}$ blood group in 436 cases and 500 controls was B (39\%), O (29.6\%), A (23.8\%), AB $(7.8 \%)$ and $\mathrm{B}(38.7 \%), \mathrm{O}(29.3 \%) \mathrm{A}(22.6 \%)$ and $\mathrm{AB}$ $(9.1 \%)$ respectively. No significant association was found to exist between blood groups and COVID-19,
RT-PCR positivity $(p>0.05)$. These findings were not aligned with findings of study conducted at Wuhan which displayed a percentage distribution of $37.8 \%$, $26.4 \%, 10 \%$ and $25.8 \%$ for $\mathrm{A}, \mathrm{B}, \mathrm{AB}$ and $\mathrm{O}$, respectively. A statistically significant association was found between ABO blood groups and COVID-19 infection ( $p$ $<0.001)^{15}$.

Results of the study conducted by Peng et al, showed that patients with the blood group of type $\mathrm{O}$ had lower risk of severe COVID-19 infection. Severity of disease among patients with blood group O compared with non-blood group $\mathrm{O}$ was statistically significant $(p=0.044, \mathrm{OR}=0.38)^{20}$. Another study showed that European individuals with non-O blood groups are more susceptible to COVID-19 and it predisposes them to severe COVID-19 with respiratory failure ${ }^{21}$. Findings of this study are aligned with above, as a week negative association was found to exist between $\mathrm{O}$ and non-O blood groups $(\mathrm{OR}=1.07)$ regarding susceptibility to acquire infection. However, this finding is only due to chance and statistically insignificant $(p>0.05)$. This inconsistency of results can be attributed to differences in both populations.

Ad'hiah et al found that association between $\mathrm{ABO}$ blood groups and COVID-19 is not influenced with age $^{22}$. In this studyABO blood groups in COVID-19 cases and controls were analyzed after stratification to age groups $(0-18,19-60$ and $>61$ year $)$ and statistically significant association was observed between age groups and Susceptibility to COVID-19 infection. However, findings of this study are supported by a Chinese study, in which $\mathrm{ABO}$ blood group frequencies showed insignificant differences among COVID-19 cases divided into 2 age groups ( $<40$ and $\geq 40$ years $)^{23}$.

Association analysis between COVID-19 and ABO blood group revealed week negative association between $\mathrm{O}$ and non-O blood groups (OR=.95), $\mathrm{A}+$ and $\mathrm{A}-$ antigen $(\mathrm{OR}=.97)$ and $\mathrm{Rh}+$ and $\mathrm{Rh}-$ factor $(\mathrm{OR}=0.93)$. A weak positive association was found between $\mathrm{B}+$ and B-antigen (OR=1.07) and COVID-19 infection. However, no significant association was found to exist between $\mathrm{ABO}$ and Rh blood groups and COVID-19 infection. Whereas in a research conducted by Fan et al, a statistically significant difference for blood type A ( $p=$ 0.04, OR=1.33, 95\% CI=1.02-1.73) was observed 24 .

Regarding Rh phenotype, week negative association was observed between Rh + and COVID-19 infection $(\mathrm{OR}=0.93)$ in this study. This finding supports the findings of another study done in Afghanistan that highlighted strongly increased risk of COVID-19 infec- 
tion among Rh- phenotype (OR=2.97, 95\% CI 1.86-3.89, $p<0.001)^{25}$.

\section{LIMITATIONS OF STUDY}

The non-disease status of control group was confirmed on basis of history only. Screening of control group through Rapid antigen testing or by RT-PCR should ideally be done to rule out presence of subclinical illness among control group. Secondly, this is single centered study done on walled entitled population, the results cannot be generalized.

\section{CONCLUSION}

In this study no significant association is found to exist between $\mathrm{ABO}$ and $\mathrm{Rh}$ blood groups and susceptibility to acquire COVID-19 infection. These findings highlight the importance of preventive practices, COVID-19 risk communication and public education. All cases of COVID-19 must be treated vigilantly irrespective of blood group and clinical presentation considering mortality associated with it.

\section{CONFLICT OF INTEREST}

This study has no conflict of interest to be declared by any author.

\section{REFERENCES}

1. Fan BE, Chong VCL, Chan SSW, Lim GH, Lim KGE, Tan GB, et al. Hematologic parameters in patients with COVID-19 infection. Am J Hematol 2020; 95(6): E131-34.

2. Ljungman P, Mikulska M, de la Camara R, Basak GW, Chabannon C, Corbacioglu S, et al. The challenge of COVID-19 and hematopoietic cell transplantation; EBMT recommendations for management of hematopoietic cell transplant recipients, their donors, and patients undergoing CAR T-cell therapy. Bone Marrow Transplant 2020; 55(11): 2071-76.

3. Sahu KK, Siddiqui AD, Cerny J. COVID-19 pandemic and impact on hematopoietic stem cell transplantation. Bone Marrow Transplant 2020; 55(11): 2193-95.

4. Gérard C, Maggipinto G, Minon JM. COVID-19 and ABO blood group: another viewpoint. Br J Haematol 2020; 190(2): e93-94.

5. Zaidi FZ, Zaidi ARZ. COVID-19 and the ABO blood group connection. Transfus Apher Sci 2020; 59(5): 102838-45.

6. Zeng X, Fan H, Lu D, Huang F, Meng X, Li Z. Association between $\mathrm{ABO}$ blood groups and clinical outcome of coronavirus disease 2019: Evidence from two cohorts Severe acute respiratory syndrome coronavirus 2 ( SARS-CoV-2 ) has become the third most common coronavirus that causes large-scale infection. 2020 [Internet] Available at: https://www.medrxiv.org/content/ 10.1101/2020.04.15.20063107v1. full.pdf

7. Cooling L. Blood groups in infection and host susceptibility. Clin Microbiol Rev 2015; 28(3): 801-70.

8. Chakrani Z, Robinson K, Taye B. Association between ABO blood groups and helicobacter pylori infection: a meta-analysis. Sci Rep 2018; 8(1): 1-11.
9. Batool Z, Durrani SH, Tariq S. Association of ABO and Rh Blood group types to hepatitis b, hepatitis c, HIV and syphilis infection, a five year' experience in healthy blood donors in a tertiary care hospital. J Ayub Med Coll Abbottabad 2017; 29(1): 90-92.

10. Jing W, Zhao S, Liu J, Liu M. ABO blood groups and hepatitis B virus infection: A systematic review and meta-analysis. BMJ Open 2020; 10(1): 1-8.

11. Zhao J, Yang Y, Huang H, Li D, Gu D, Lu X, et al. Relationship between the ABO Blood Group and the COVID-19 Susceptibility. Med Rxiv 2020; 1(1): 1-18.

12. Dzik S, Eliason K, Morris EB, Kaufman RM, North CM. COVID19 and ABO blood groups. Transfusion 2020; 60(8): 1883-84.

13. Zietz M, Zucker J, Tatonetti NP. Associations between blood type and COVID-19 infection, intubation, and death. Nat Commun 2020; 11(1): 1-27.

14. Göker H, Aladă̆-Karakulak E, Demiroğlu H, Ayaz CM, Büyükaşik Y, Inkaya AC, et al. The effects of blood group types on the risk of COVID-19 infection and its clinical outcome. Turkish J Med Sci 2020; 50(4): 679-83.

15. Zhao J, Yang Y, Huang H, Li D, Gu D, Lu X, et al. Relationship between the $\mathrm{ABO}$ blood group and the coronavirus disease 2019 (COVID-19) susceptibility. Clin Infect Dis 2020; 2019(Xx Xx): 1-4.

16. Ellinghaus D, Degenhardt F, Bujanda L, Buti M, Albillos A, Invernizzi $\mathrm{P}$, et al. The $\mathrm{ABO}$ blood group locus and a chromosome 3 gene cluster associate with SARS-CoV-2 respiratory failure in an Italian-Spanish genome-wide association analysis. Med Rxiv 2020 [Internet] Available at: https://www.medrxiv. org/content/10.1101/2020.05.31.20114991v1.full.pdf

17. Noor A, Tashfeen S, Akhtar F, Anwar N, Din HU, Akhtar F. Association of Covid-19 With Abo Blood Groups In Tertiary Care Center of Pakistan. Pak Armed Forces Med J 2020; 70(1): 251-55.

18. Abdollahi A, Mahmoudi-Aliabadi M, Mehrtash V, Jafarzadeh B, Salehi M. The novel coronavirus sars-cov-2 vulnerability association with abo/rh blood types. Iran J Pathol 2020; 15(3): 156-60.

19. Khalil A, Feghali R, Hassoun M. The Lebanese COVID-19 cohort; A challenge for the ABO blood group system. Front Med 2020; 7(11): 1-7.

20. Peng M, Huang S, Zhu S, Chen C, Qin J, He M, et al. Distribution of ABO blood groups and association to low risk of COVID-19 infection in patients 2020; 1(1): 1-16.

21. Valenti L, Villa S, Baselli G, Temporiti R, Bandera A, Scudeller L, et al. Association of $\mathrm{ABO}$ blood group and secretor phenotype with severe COVID-19. Transfusion 2020; 60(12): 3067-70.

22. Ad'hiah AH, Abdullah MH, Alsudani MY, Shnawa RMS, AlSa'ady AJR, Allami RH, et al. Association between ABO blood groups and susceptibility to COVID-19: profile of age and gender in Iraqi patients. Egypt J Med Hum Genet 2020; 21(1): 1-10.

23. Wu Y, Feng Z, Li P, Yu Q. Elsevier has created a COVID-19 resource centre with free information in English and Mandarin on the novel coronavirus COVID-19. The COVID-19 resource centre is hosted on Elsevier Connect, the company's public news and information. Since 2020.

24. Fan Q, Zhang W, Li B, Li DJ, Zhang J, Zhao F. Association between ABO blood group system and COVID-19 susceptibility in Wuhan. Front Cell Infect Microbiol 2020; 10(5): 1-7.

25. Saify K, Alborz MS, Saadat M. Susceptibility to the novel coronavirus disease (COVID-19) is associated with ABO and Rh blood groups: a case-control study from Afghanistan. Egypt J Med Hum Genet 2021; 22(1): 1-5. 